sicians as those who were members of the memorable committee of 1847, and how irrational and unjust the "revisers" are to strive to abolish the admirably written system of morals unanimously adopted by the Association as a condition of membership! It is more than likely that any man who, in future, may be so rash as to endeavor to change the maxims, language or arrangements of the American Code of Medical Ethics, will be the subject of general opprobrium and derision.

15. One or two more notes will terminate this general examination of the "revised" Code. It does not seem possible for any individual or committee to improve the fundamental maxim of the Code which is, "be just," and is the basis of all codes of good morals. Any deviation from this maxim which is probably as ancient as the first aggregation of men, must necessarily be bad, for it will inevitably resolve itself into-be unjust.

16. Peace is not likely to be restored in the Association until the disorganizers are out-voted, the transformed Code is rejected, the original Code is preserved in its integrity, ethical wrangles are discouraged, and the revision question is disposed of forever.

17. Questions such as these can not always be discussed without warmth, particularly when they are raised by disturbers of the peace of a large and respectable body of men. Made in the interest and for the welfare of the Association whose objects would suffer by the adoption of a perverted Constitution, and whose dignity would be offended by an immoral, ill-composed and ridiculous Code, this criticism is of necessity unsparing. The writer regrets to have been compelled to use the strong expressions which the iniquitous revision agitation seem to justify, but was prompted to do so entirely for the defense of justice against injustice, without any attempt to conceal his indignant sorrow for those who are willingly led by designing demagogues, without desire to omit any demonstrations of grievous pity for them, and without power to suppress the distressful feeling that the Assocration will see evil days if the wrong-doers prevail. In his defense of good morals the writer found it necessary to point out the blunders in both the spirit and the letter of the "revised" Code, and to bring to light the enormities of the disorganizers and the incapacity of the revisers, not as individuals, but all together as the willing agents of a turbulent and mischievous faction.

A. Conservative Member.

\section{"The Texas Medical Law."}

To the Editor:-I have to thank you for calling my attention to an editorial article in the current number of the Texas Medical Journal, in which the Illinois state Board of Health is accused of having made "a bad break with regard to the law in Texas," in its report on medical education, prepared by the present writer. Since that report has not yet been published the Texas Journal must refer to an article originally published in the Journal of the American Medical Association, March 10, 1894, under the title "Legal Requirements for the Practice of Medicine in the United States." It is, therefore, proper that this notice of the Texas Journal's charges should appear in the same columns.

The article consisted substantially of "a résumé of the legal requirements for practice in each State and Territory of the United States in force Jan. 1, 1894," and in it appeared the following:

"Texas.-A license issued after examination by a District Board of Medical Examiners. Diplomas confer no right to practice."

This was stated to be the law in force in Texas, Jan. 1,
1894 - the "legal requirement" for the practice of medicine in that State.

The Texas Medical Journal now asserts that this is a mistake due to ignorance, for which there can be no excuse, and adds :

"It is notorious that the Texas law requires nothing but a diploma (a license can be procured by virtue of it alone) and the clerk of the county court is the judge of that diploma, even though it be written in Latin and he is unable to read it."

The Texas Civil Statutes, in force on the first day of January, 189t, has the following under "Title 73-Physicians":

Article 3632. Duty of board to examine applicants, etc. It shall be the duty of said board [one of the District Boards of Medical Examiners authorized to be created by a preceding article] to examine thoroughly all applicants for certificates of qualification to practice medicine in any of its branches or departments, whether such applicants are furnished with medical diplomas or not, upon the following named subjects, to-wit: Anatomy, physiology, pathological anatom and pathology, surgery, obstetrics and chemistry; but no preference shall be given to any school of medicine. (Const. Art. 16, §31; Act Aug. 21, 1876; 15 [eg. p. 221.)

There is no disposition on the part of the writer to evade responsibility for any sins of omission or of commision in the report on medical education; doubtless there are such, but the Texas Medical Journal is not dealing with one of them in this instance. The report must be judged for what it is, not for what it might be. In the résumé in question it was undertaken to state what the law required of medical practitioners-not whether the law was good or bad, efficient or inoperative, well enforced or neglected.

As a matter of fact, so stated in previous reports on medical education by the Illinois Board since 1883, the Texas law is a dead letter-whether so through the supineness or indifference of the profession it is not undertaken to say. But it may not be out of place to suggest that one, if not the only, difficulty in the enforcement of the Texas medical law as it stands to-day on the statute books-requiring a thorough examination of all applicants, "whether such applicants are furnished with medical diplomas or not"-has arisen from the acts of the compilers of the Penal Code of Texas.

The penalties for practicing before having obtained and recorded a certificate or license from the proper District Board of Medical Examiners, as provided in the article above quoted, are referred, in Article 3638, to the Penal Code. In the compilation of this Code in 1879 , three years after the medical practice act went into effect, there appears a chapter entitled, "Ch. 3.--Unlawful Practice of Medicine." It consists of four articles, framed, as is specifically stated, upon the medical practice act of 1876 . The first article, numbered 396 in the Code numbering, prescribes the penalty for practicing without having obtained the certificate of qualification; 397 defines what constitutes a separate offense; 398 fixes the penalty for failing to file the certificate; 399 defines the classes of practitioners who are exempt from the provisions of the Act-those qualified un. der the Act of 1873 , those in practice five years prior to Jan. 1,1875 , and midwives.

It will be seen that the important articles are 396 and 398 . Article 396 is as follows :

"If any person shall practice for pay, or as a regular practitioner, medicine in this State, in any of its branches or departments, or offer or attem pt to practice without first having obtained a certificate of professional qualification from some authorized board of medical examiners [or without having a diploma from some accredited medical college, chartered by the Legislature of the State, or its authority, in which the same is situated], he shall be punished by fine not less than $\$ 50$ nor more than $\$ 500$."

As already stated, the compilers of the Code distinctly announce that the Articles composing this chapter "are framed upon the Act of Aug. 21, 1876." 
Nowhere in that Act, either directly or by implication, is there any warrant for the phrase above bracketed in the quotation of Article 396. Not only is there no warrant in that Act for recognizing as an alternative qualification "a diploma from some accredited medical college," but the Act expressly forbids such recognition. All applicants for license to practice medicine in Texas are required by the law (Article 3632) to submit to be thoroughly examined in certain specified branches, "whether such applicants are furnished with medical diplomas or not." Article 3637 categorically defines the classes which are exempt from this examination; holders of diplomas are not therein exempted. Article 3638 is cumulative on this point.

The bracketed clause is an unwarranted and mischievous interpolation. The only other important Article of the compilers (398) was held by the court (French vs. S. 14 App. 75.) to be inoperative because "irreconcilably in conflict with the Act of 1876," and a modification was made to bring them in harmony. Can it be doubted that if the question was raised, Article 396 would also be held to be "irreconcilably in conflict," not only with Article 3632 but with the expressed purpose and policy of the Act as a whole?

F. W. REILLY, M.D. Chicago, April 16, 1894.

Ex.Sec'y Ill. State Board of Health.

\section{From a Woman Physician.}

An Open Letter to Dr. W. W. Parker. Conant, Lake Co., Florida, April 6, 1894.

With the courtesy of a Virginia gentleman, and there are none more courteous, and with the fairness of age and experience, will Dr. Parker listen to $\mathrm{my}$ story, and hear $\mathrm{my}$ plea, before he utters sentence against me-a woman physician?

My first year as doctor was spent as interne in a hospital conducted by women for women. During the year there were nearly one hundred births, two-thirds of which were illegitimate. The rules of the institution admitted only unfortunate girls who were primipara. No mother was permitted to leave without her child, nor child without its mother, if both were living. There I heard their stories; shall I repeat them?

An ignorant child of fourteen a mother! What is the age of legal consent in your State? A domestic chloroformed in an institution having male physicians; a girl overpowered in a reputable physician's office. These for variety, with the host of deceived by promise of marriage.

Afterward, I was the woman physician in an institution employing one woman and several male physicians. Complaint after complaint was poured into my ears by young women patients, of insult and vile insinuation from one of the doctors. Reporting to headquarters, as I learned from my predecessor's experience, called for an occasional apology on the part of the offender and then was made the subject of merriment and rude jest. Could Dr. Parker have stood in my place and noted the obscene look and unhallowed touch in the gynecological consulting room, I believe he would have felt like striking. Babes were not in the program there. I would not insinuate farther, for my position and opinions were too thoroughly ' understood for me to know more. When the situation became unendurable I was told that if these things were the cause of my resigning I would not better myself, as I would find the same conditions everywhere. One of the younger physicians who seemed a Christian gentleman, told me that he had been as much shocked as $I$, at first, but had found that all men told their jokes and their dirty story, and he had come to tell his with the rest.

I learned afterward of his death. The immediate cause was said to have been grief over the death of his young child from blood poisoning.

Settling in a town with upwards of a dozen male practitioners, I was asked by one what I would do if appealed to by an unfortunate girl. I replied: "Nurder is murder. I would as soon take a child from its crib and dash its brains out, as to destroy the youngest fetus." He replied: "There is not a doctor in town but has and will do it. You are no friend to your sex." I had no reason to contradict his first statement, but as to the last I loved woman too well to help her add murder to her other sin. If mother love and the touch of baby fingers did not save her to God and womanhood nothing could. That it could, I had proof in many cases where forsaken mothers had, in spite of all, carved for themselves and their fatherless children an honorable place in the world.

He gave me to understand that he had two abortion cases on hand and had asked with a view to my helping him out. In a practice of thirteen years, I can remember being appealed to just twice-both times by women who had never seen me before-one a girl; one a wife with the consent of her husband. The unfortunate girl vanished as she came, plus the memory of a few earnest words. The wife was delivered of a fine child in due time.

The Doctor strikes a strong blow in a much needed direction when, in reference to "the preventive treatment against children," he says: "We are standing upon the mouth of a volcano wider than Vesuvius." And with all my woman's heart and brain I honor him for it, as I reverence and honor the God-like in man, but since as a girl I cried with my pet cat over her dead kittens-killed by a neighboring tom cat -I have never seen cause to hold the male element less responsible for the slaughter of the innocents than in the days of Herod.

Then, as now, men seem to fear the coming of Christ born of woman, to dethrone earth's sensuality and cruelty.

This is my plea: "What God hath joined together let not man put asunder," in the medical profession or elsewhere.

Let men and women join forces under the banner of Him who said: "He that is without sin among you, let him first cast a stone at her ;" and also: "Neither do I condemn thee; go, and sin no more."

Let us join forces all along the line, and fight this hydraheaded monster to the death and save our nation.

O.E. WORCESTER, M.D.

\section{For a Medical Jury.}

Bracketrville, Texas, April 15, 1894.

To the Editor:-I hasten to the support of the suggestion of your New York contributor (in No. 13 current volume) for a revision of the statutes in a manner to provide for "a jury of medical men in all cases where medical evidence is required." I would establish at least one such jury in every county. I would arraign for trial all professors of clinical morphology, wherever they may be found at large, and all speculators on the psycho-physical relations of man, whether in the East or West. I would not try them by rule of law, but simply attempt to find out what is the matter with them. "If it is the physician's business intelligently to treat disease, then here is a fine field for future development." The jury would be required to clear and determine such questions as this: What is the mental condition of a medical man who writes about another to the JourNaL that " his work was fruitless, not because it did not have all the elements of truth, active and professional disgrace (to quell) ; but because of the apathy of the profession itself." And again, "he ate largely of oatmeal which of itself is a paralyzing food." And again, "while it is right to use all 